Journal of Language \& Translation 10-1

March 2009, 7-44

\title{
Translation and Cultural Equivalence: A Study of Translation Losses in Arabic Literary Texts
}

\author{
Hanada Al-Masri \\ Cornell University
}

\begin{abstract}
This article focuses on cultural translation, especially addressing the issue of cultural inequivalences or losses occurring in the translation of Arabic literary texts. The aim of this study is to investigate the translation strategies that led to cultural losses and to emphasize the important role of the translator as a cultural insider. The corpus is based on a collection of Arabic short stories written by Youssef Idris (1991). In order to illustrate cultural aspects in literature, we analyze figurative language (metaphors, idiomatic expressions, proverbs) in two texts: Arabic (the source text) and English (the target text). We argue that figurative language and cultural terms are unfamiliar and so are marked to the target reader on the grounds of the unmarked and should be looked at from the perspective of a cultural insider. The data is analyzed within Pike's (1954) etic-emic approach to translation. The analysis has shown that translation of the source text was communicatively successful. However, it failed to represent the culture-bound and emotionally charged words which represent the implicit/emic level of the source text. The translator has failed to complete the cycle of etic-emic-etic, and so remained an outsider to both the source and target texts. The study
\end{abstract}

\footnotetext{
*This article is based on a $2004 \mathrm{PhD}$ dissertation.
} 
concludes with the implication that a translator has to assume the role of a cultural insider for both texts in order to render a culturally more faithful translation.

Keywords: cultural translation, translation problems, translation and equivalence, etic-emic concepts, markedness theory, Arabic short stories.

\section{Introduction}

Cultural understanding during the process of translation is extremely essential especially in the translation of literary texts, which require an effort on the part of the translator to retain the cultural information (reflected mostly in the figurative language) of the source text in the target text. Such cultural translation is known to be one of the most challenging aspects of translation (Larson 1984; Farghal 1995; Baker 1996; Buchowski 1996; Anderson 2003). It involves the translation of linguistic structures as a part of culture, in which the translator takes into account not only the equivalence of meaning, but also investigates higher levels of content, context, semantics, and pragmatics.

This article investigates 'cultural losses' occurring in the translation of Arabic literary texts. We discuss the strategies adopted during the translation process to see how the decisions taken led to a loss of the source culture (henceforth cultural losses). We propose the three primary arguments. First, cultural losses or inequivalences result mostly from overlooking the literariness or figurativeness of the source text. Omitting or altering the figurativeness (cultural metaphors, idiomatic expressions, and proverbs) of the source text is particularly sensitive in literary translation and will result in a translation that is unfair to the source text, the source culture and the target audience. Second, we argue that cultural losses are losses on the deep symbolic level, or the 'emics' of the source language (Pike 1954), hence, they 
require an effort on the part of the translator to retain these emics and capture the cultural implications meant by the source author. Accordingly, the translation product would be culturally more suitable if the translator assumes the function of a cultural insider. Finally, cultural losses are context-sensitive, they are, by and large, losses of the unfamiliar and so are marked to the target readers.

In this article, we first introduce a general review of literature on figurative language and the etic-emic approach, then, we proceed with an analysis and discussion of cultural losses, finally, we investigate the losses from the viewpoint of markedness theory and propose a graded continuum of these losses.

\section{Related Literature}

\subsection{Figurative Language (Metaphors, idioms and proverbs)}

The term 'metaphor' was originally coined by the great Greek philosopher Aristotle, who saw the power of metaphor in allowing people to produce knowledge. It is traditionally defined as "the use of a word or phrase denoting one kind of idea or object in place of another word or phrase for the purpose of suggesting a likeness between the two" (Danesi \& Perron 1999: 162). This traditional analysis of metaphor has assumed that metaphor involves a deviation from ordinary and straight-forward usage of language in order to cause a change in meaning based upon similarities between two things. Later on, the concept of metaphor developed, in which it was no longer viewed as a verbal ornamentation or a stylistic device; rather, it has become realized as an effective device in communication. George Lakoff \& Mark Johnson (1980), forerunners in proving the presence of metaphors in everyday thought and discourse, rightly propose that metaphor is a verbal representation of abstract thinking in everyday life. In their insightful research, they argue 
Metaphor is for most people a device of the poetic imagination and the rhetorical flourish-a matter of extraordinary rather than ordinary language. Moreover, metaphor is typically viewed as characteristic of language alone, a matter of words rather than thought and action... we have found, on the contrary, that metaphor is pervasive in everyday life, not just in language but in thought and action (Lakoff \& Johnson 1980: 3).

Researches and theorists have viewed 'metaphor' from different perspectives. Some of the most salient theories on the topic are presented in Way (1991). Emotive theories, for example, view metaphor as a deviant use of language and one which can have no real cognitive meaning. Their argument is based on excluding metaphor from descriptive and scientific discourse, and denying any cognitive content to metaphor, focusing instead on its emotional side. The Substitution approach holds that a metaphorical expression is used in place of an equivalent literal expression. As such, the cognitive content of metaphor is reduced to its literal meaning. It follows, metaphor is merely an ornamentation device chosen by the author instead of its literal equivalent.

This view was later developed into the Comparison theory, which viewed metaphor as a form of ellipsis (an elliptic simile), a shortened form of literal comparison. According to Way (1991: 34) the comparison view of metaphor is more sophisticated than that of the substitution approach since metaphor is not a mere substitution of terms, rather a comparison between two things. According to the Controversion (or Verbal-Opposition) theory, metaphor is viewed as some kind of logical contradiction between terms. That is to say, whenever an utterance is false, or self-contradictory, the hearer looks for secondary levels of meaning (i.e., the connotations of the term). Danesi \& Perron (1999: 164) believe that such a connotative meaning poses a dilemma because "it is not the denotative meaning 
of the vehicle that is transferred to the topic, but rather its connotations and annotations... it is this complex system of historicallyinherited connotations that are mapped onto the topic." Way (1991: 43) points out that the weakness of this approach lies in dealing with metaphor without reference to any extra-linguistic considerations.

A later development occurred in the Interaction theory. According to this view, metaphor is viewed as the interaction of two domains: the literal primary subject, and the metaphoric secondary subject, where the associated ideas and implications of the secondary domain are transferred to the primary system. Way points out that the interaction view carries the implication that "our concepts carry with them a set of associated ideas and beliefs even when they are used in their literal sense" (48). This, she believes, has the merit of looking at metaphor as a whole system of concepts, not just the terms of the tenor vehicle.

Idioms, on the other hand, are generally viewed in the literature as a special category of lexical items which are not only determined through their structure, but also show a specific type of behavior in language use (Strässler 1982: 11). An idiom is traditionally defined as "an expression whose meaning cannot be worked out from the meanings of its constituent words" (Trask 1999: 119). Strässler (1982) points out that there are few studies dealing with idiomacitya general term referring to the syntactic and semantic properties of idioms - although it is not a new subject in linguistics. He mentions that most of the works on idioms are collections that do not comprise a unified theory of idioms. Strässler comments "the general lack of idiomatic theories might certainly be a reason, for it is extremely difficult to incorporate an ill-defined phenomenon into a new concept" (26).

Weinreich (1969: 42) refers to the idiom as "A phraseological unit that involves two polysemous constituents, and in which there is a reciprocal contextual selection of subsenses." Makkai (1972) in Strässler (1982: 43) describes idioms as "unitary in meaning, 
unpredictable as to syntax, and complex, hence misleading in expression".

Hockett's (1958) classifies idioms into: monomorphemic lexemes, polylexemic lexemes, phrases, proverbs, allusions, and abbreviations. Katz and Postal (1963: 30) identify two types of idioms: "lexical idioms" and "phrase idioms."

Way (1991: 10) draws on the connection between idioms and metaphors. She states "idioms, like metaphors, do not always mean what they literally say. But with idioms we have a strong bias to perceive only the nonliteral meaning and ignore the literal one".

Both Pedersen (1988) and Newmark (1991) relate idioms to collocations. Pedersen (132) remarks that collocations and idioms represent one of the areas of language where grammar and lexis overlap. He refers to 'restricted collocations' or 'semi-idioms', where one word is used figuratively, and which often shows variation. Newmark (1991) identifies idioms with collocations on the grounds that they constitute groups of collocated words whose meaning is not clear from the common meanings of their constituent words. He argues, accordingly, that "any literal translation of such idioms into another language is more often than not nonsense" (58). Other researchers referred to types of idioms like: pure idioms (invariable), and figurative idioms (which often admit some variation, like replacing one word of the idiom by another). In addition, we believe that there are some chunks of words that might not be exactly idiomatic, yet at the same time could not be translated word for word.

In comparison to metaphors and idioms, less literature was found on proverbs. Brown et al (1998: 525) generally define proverbs as "the short, generally known, sentences of the folk that contain wisdom, truths, morals and traditional views and which are handed down orally from generation to generation". Bakalla (1984: 248) adds to this definition that a proverb is "often used colloquially and set forth in the guise of a metaphor and in the form of a rhyme, and is sometimes alliterative." Accordingly, proverbs can be looked at 
as illustrations of contexts, not a representation of a particular one. In other words, they are not limited to one context in the source language, rather they are used over and over, and are extended to many variable contexts because of the morals they teach, or their "folk wisdom," as anthropologists prefer to describe them.

We have briefly introduced the definitions and salient theories of metaphors, idioms and proverbs which represent the corpus of cultural losses occurring in this study. In what follows, we will introduce Pike's (1954) theoretical framework within which these loses will be analyzed and discussed.

\subsection{Pike's (1954) Etic-Emic Approach}

The concepts of 'etic' and 'emic' - the Outsider and the Insiderare probably what is Pike (1954) best known for. The term 'etic', derived from "phonetic" in linguistics, refers to the analysis of language sounds. 'Emic', on the other hand, is derived from "phonemic", and designates culture-bound, or language bound units of analysis. The terms 'emic' and 'etic' were created out of "a need to include nonverbal behavior in linguistic description" (Pike 1990: 30). Pike created the two terms to describe his anthropological research. More specifically, he (1990: 28) used the term 'emic' to refer to "a physical or mental system treated by insiders as relevant to their system of behavior and as the same emic unit in spite of etic variety." 'Etic', on the other hand, donates "an approach by an outsider to an inside system, in which the outsider brings his own structure-his own emics-and partly superimposes his observations on the inside view, interpreting the inside in reference to his outside starting point" (30).

The terms were later widespread and popular in different academic disciplines other than linguistics and anthropology by the end of 1980s: sociology, folklore, semiotics, cross-cultural research, ethnography, psychology, and many others (Headland, 1990: 18). Berry (1990) 
for example, applied Pike's concepts to reach a theoretical generalization in psychology. He (87-88) proposed a three-step sequence representing "etic-emic-etic", or 'imposed etics'-'emics''derived etics', respectively. According to this sequence, the psychologist moves from etic presuppositions to gradually closer approximations of culturally specific concepts to recovery of those concepts, which become etic or derived etics notions.

In this article, we apply Pike's (1954) concepts of 'etics' and 'emics' to the analysis of cultural losses in translation. They are pertinent to our discussion since they express the interplay between rules of analysis (language) and actual practice (culture). Following Pike (1954) and Berry (1990), we argue that in order to achieve cultural equivalence in translation, the translator starts with an emic understanding of his own cultural experience and knowledge and then uses it as an etic approach (surface level) to represent the source-language phenomena in the target culture (i.e., the translator moves from being an outsider to an insider of the target culture). The translator is still in the process of conceptual behavior so the analysis is still emic not etic. The sequence continues by a process of learning about the phenomenon in the target culture in the sense it is employed by target people. Finally, the source emic understanding (from the translator's own culture) and the new emic understanding (from the target culture) are compared, if there are shared features to both, then an etic understanding can be achieved that is suitable for describing and interpreting the phenomenon in both cultures. To put it differently, both the 'etics' and 'emics' of the source language should be accounted for during the translation process to reveal facts about events in the source culture, and deep meanings of the source language, respectively. 


\section{Definitions and Methodology}

\subsection{Definitions}

For the purposes of this article, cultural losses are broadly defined as the losses of cultural norms, religious beliefs, social customs, and proverbial wisdom that are inherited through generations and comprise the identity of the source culture. Such losses occur during the process of correlating the verbal signs of one culture to another different culture and result mainly from misrepresenting the literariness of the source text and its pragmatic forces. Cultural losses could be explicit (causing a loss of the cultural meaning of the source text both on the surface and deep levels), implicit (causing a loss on the deep level/ concealed cultural information), modified (altering the realities of the source text, as experienced by the source readers), or complete (deleting cultural characteristics that are unique to the source language).

It is assumed that cultural equivalence depends on the degree of relatedness between two languages that represent two different cultures. In this article, the source-text language (Arabic, a Semitic language) and the target-text language (English, a Germanic language) are far from being related, and so have no direct influence on each other due to the geographical distance (cf. Pedersen 1988, for more on the concept of distance). Therefore, cultural and religious differences between the two languages are expected to be extreme, and any translation process between the two is, to say the least, challenging. In this case, pragmatic forces like 'shared knowledge' and 'context of situation' gain primary roles in understanding the translation product. The data in this article reflect how the shared world between the source language and the target language "shrink to the extent of becoming merely hypothetical" (Dorbzynska 1995: 598). This entails an effort on the part of the translator to provide some common background and to account for context-sensitive expressions. 


\subsection{Data}

The corpus of this article is based on Youssef Idris's (1991) collection of contemporary Arabic short stories. The writer, Youssef Idris, is one of the most remarkable contemporary writers in Egypt. $\mathrm{He}$ is a major exponent of the radical movement from romanticism to committed realism in modern Egyptian literature, particularly in the field of short fiction. His familiarity with the masses makes him feel at home with the crowd and enables him to capture the everyday essence of Egyptian society. His literary production is derived from daily life situations, which are dramatized through the artistic touches of connotations and literary devices, thus are reflections of the cultural beliefs, cognitive attitudes and social costumes of the Arabic/Egyptian culture. This makes his works interesting from a translational viewpoint and excellent material for cultural analyses.

The collection chosen here is entitled Three Egyptian Short Stories (Thalath Qisas Misriyah) that includes: "Farahat's Republic," "The Wallet," and "Abu Sayyid". The English version of this collection is translated by Saad El-Gabalawy who is a native speaker of Arabic and is known for his accuracy, clarity, and naturalness.

It is worth noting that the language of the Arabic collection is a combination of Modern Standard Arabic and dialectical Egyptian Arabic. The importance of this comes from the diaglossic situation of Arabic. At the social level, each of the two varieties has certain spheres of social interaction assigned to it, and in the assigned spheres it is the only socially acceptable variety. The inclusion of dialectical Arabic in the writings of Youssef Idris allows for the community's present day vernacular to surface with all its rich and genuine cultural representation without euphemism or hedging of statements that reflect swearing, and taboo topics. This, accordingly, makes our data an interesting and rich material for translational analysis. 


\subsection{Procedures}

The data are analyzed as a complete inventory of the losses resulting from the lack of cultural equivalence in literary translation. They are analyzed within the comparative and the analytical frameworks. Newmark (1991: 163) argues that "the only way to assess the deficiencies of the translation is to examine the linguistic differences between it and the original". The comparative method aims at comparing two versions of the same text (Arabic as the source-language text and English as the translated text). The resulting losses will then be compared and categorized on the continuum of markedness. This analysis is expected to give insights onto texts as reflections of culture. The analytical method, on the other hand, is conducted by means of a close analysis of examples, not so much to pass judgments on the product, rather, to analyze the strategies adopted by the translator and how they led to cultural losses.

\section{Results and Discussion}

\subsection{Results}

An investigation of the translation product shows cultural losses were the result of four translation strategies. The first is literal translation, in which the translator opted for word-for-word translation of cultural expressions that do exist in the target culture yet carry different connotations in the source text. Disregarding such connotations result in rendering an unintelligible translation to target readers. This strategy is illustrated in 'explicit losses' (e.g., 1-2). Second is adaptation in which source-language elements are replaced by equivalent targetlanguage elements to achieve equivalence. Adaptation also took the form of replacement of cultural idioms in the source text by one verbal sign in the target text, thus failing to transfer the source- 
language view of the world. This strategy rendered equivalence only on the surface level and failed to account for equivalence on the deep level. Examples are 'implicit losses' (e.g., 3-8) and 'modified losses' (e.g., 9-12). Third is deletion. Here the translator completely deleted culture-bound terms. This strategy is illustrated in 'complete losses' (e.g., 13-14), where source language signs had no cultural or linguistic equivalents in the target language. This negatively affected the vividness of the metaphoric and idiomatic expressions of the source text. Fourth is over familiarity with the source language which altered the style of the source language text from an implicit conservative style to an explicit direct style in the target language text. As such, translation neutralized or leveled out the pragmatic effects of the figurative language of the source text.

It is noted that the translator opted for free translation of cultural elements. He chose not to paraphrase or provide extra information to the target readers in certain situations where in fact such strategies would have been more fitting to avoid cultural losses. A more detailed analysis of how these strategies negatively affected translation will be presented in the following sections.

\subsection{Classification and Analysis of Cultural Losses}

Cultural losses form a hierarchy of losses classified into four main categories: explicit losses, implicit losses, modified losses, and complete losses. The classification is based on the degree of cultural information lost (affecting the source language text both on the surface and deep levels). It must be pointed out that this classification is by no means absolute, nor has a clear-cut boundary, for one loss may be classified as both linguistic and cultural, depending on the perspective of analysis (verbal losses versus cultural losses). This, however, emphasizes the wedlock and interconnectedness between language and culture, where the separation of the two is unrealistic. 


\subsubsection{Explicit Losses:}

'Explicit losses' refer to any loss of cultural information both on the surface level (the verbal signs and structures/ 'etics'), and on the deep level (the hidden information that are culture-specific/ 'emics') of the source text. It was observed that such losses result mainly from literal translation, whereby linguistic equivalence is achieved on the expense of cultural equivalence, thus posing major difficulties in the decoding of the meaning intended in the source message. In these losses, translation adheres to the "principle of adequacy" (Toury 1986: 1123), but violates the "equivalence effect principle" (cf. Farghal, 1995b: 54). These 'linguistic gaps', as Farghal (1995a: 198) calls them, are purely linguistic as they are present in the experiential world of the culture in question. It is argued, though, that such linguistic gaps would inevitably influence and affect the overall cultural equivalence of the source text. Explicit losses are illustrated in two examples: the loss of idioms (1) and the loss of the speaker's social attitude (2). ${ }^{1}$

" فاليو يوم الخميس...و الليلة ليلة الجمعة" (1)

"Fa al-yawm yawm al-khamees... wa al-layla laylat al-jumurah"

Thus the-today day the-Thursday... and the- eve eve the-Friday "It was Thursday night" (Abu Sayyid).

(2)

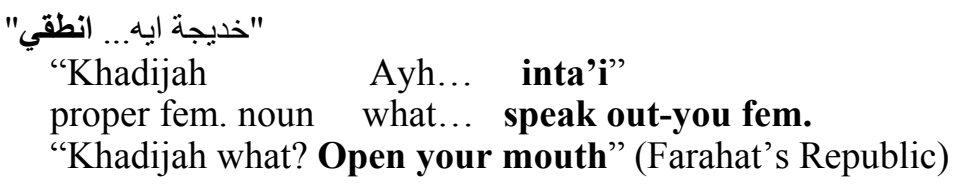

1 The examples in the body of analysis are presented in four different forms: the first line presents each example in its source-language form (Arabic), the second line is our transliteration of the example in English, the third line is our literal (word-for-word) translation of the source language, and the fourth line is the example in its English form, as reproduced by the translator. 
Examples (1) and (2) illustrate how literal translation results in an explicit loss of the source message, both on the surface level (verbal signs), and on the deep level (cultural information). The difficulty of comprehending example (1) stems from its being a cultural idiom. It is worth mentioning that the source example (1) may not represent a "pure" idiom in Pedersen's (1988: 123) sense (i.e., invariable in form). However, it is considered so since it falls within these expressions that could not be translated word for word either. Before analyzing the losses, it is important to understand the context of situation of the source language text in order to correctly decode the source message.

Example (1) shows how idioms are culture-bound and are extremely sensitive to the context of situation, as such, their translation requires a conscious decoding on the part of the translator before rendering them into the target text. The context of situation in (1) refers to the wife/character, who after having had a shower, smiled mysteriously at her husband who had long known the mystery of such a smile. The literal translation of the idiom is problematic because it fails to capture the intended meaning reflected in the idiom's context, both on the surface linguistic level, and on the deep cultural level. On the surface level, translation completely overlooks the formal and functional equivalence of 'Friday eve' rendering it into a non-idiomatic expression that is alien to the target readers. Such literal translation renders a message that is unnatural, hard to understand, and meaningless. In other words, it does not really make a difference to the target readers as to whether it is translated into, say, 'Wednesday night' or 'Monday night'.

On the cultural level, translation causes an explicit loss of the cultural values present in the source (Arabic) idiom. First, the verbal choice of 'Thursday' and 'Friday' is not merely random. Rather, it carries the functional implication for the weekend holiday, which is Friday in most Arab countries. Understanding this function leads to an understanding of the accompanying cultural implications of 
obscenity and taboo subjects. Put together, the source idiom reflects the following cultural practice: Thursday and Friday are generally the two days where a married couple is more likely to have their sexual intercourse, because the second of the two days is a holiday. In (1), the husband understands the 'mysterious' smile of his wife as a lust. Such implication might be considered odd by readers in the target culture, yet it is valid and shows how idioms are valuable reflections of the conservative nature of the source (Arabic) culture.

The translator's over familiarity with the source language in (1) led him to cognitively overlook the marked nature of the idiom. That is, what he considered familiar and unmarked turned out to be unfamiliar and marked to the target reader. I suggest, along with Anderson (2003: 393), that the translator should have detached himself from his knowledge of the familiar; i.e., defamiliarizing the familiar. This would yield a better translation that avoids losses, and at the same time preserves the source author's conservativeness. One suggestion to maintain a closer source-like understanding in translation is to use the phrase 'Saturday night', for example.

Example (2) illustrates how social attitudes are normally infused within literary texts. Again, it shows how literal translation of words, especially those that are culturally bound, causes an explicit loss of the social attitudes representing the source culture. In this example, the main character, a sergeant major, questions a woman who went to the police station to report charges of robbery and battery. During his process of investigation, the sergeant major begins by asking the woman about her first name, then commands her, in a rather superior dominant way, to give her full name. On the surface level, the source word functions rhetorically, not literally as the translation suggests, expressing the speaker's sarcastic tone towards the addressee. This loss could be understood in the light of Grice's (1975) 'conventional implicative', whereby words conventionally imply more than what they literally refer to. Although this notion is originally limited to propositional meaning (Lyons 1995: 272), it could be equally extended 
to cultural meaning on the grounds that verbal signs convey positive or negative connotations beyond their literal meaning. On the deep (cultural) level, the source word is rich in that it reflects one of the culture-bound attitudes prevailing in the source culture, namely, the attitude towards women, in general and towards those going to police stations, in particular. Culturally speaking, Arabs played down the role of women in society (cf. Farghal 1995a: 205). According to the Arabic culture, respectful women do not and are not allowedby social constraints - to go to police stations regardless of the purpose of their visit. In (2), although the woman goes to the station to report charges of robbery and battery, she is treated socially as a criminal low-class woman. This cultural information is explicitly lost in the English translation due to its focus on formal equivalence.

In short, explicit cultural losses in translation are losses of the 'etic' and 'emic' of the source text. They affect the content of the message causing a distortion in the decoding and understanding of the translated text. Accordingly, the resulting translation would be awkward, unnatural, and unclear to the target readers. In the following section, we will discuss the second type of cultural losses, 'implicit losses'.

\subsubsection{Implicit Losses}

'Implicit losses' refer to the loss of cultural information implicitly present in the source text. They are losses of the source-culture spirit, as echoed in its literary heritage. It should be pointed out that this type of losses is challenging because its understanding requires, what Bailey (1996: 152) calls, "reading between the lines". That is, target readers are expected to "search for some special possibility of hidden and certainly situation-specific interpretations". In contrast to explicit losses, where translation causes a loss both to the 'etics' and 'emics' of the source language, implicit losses are losses to the 'emics' of the source culture, and so, they are culturally-oriented. 
Implicit losses represent the following sub-hierarchy of losses: loss of idioms (3), loss of social attitudes (4), loss of social practices (5), loss of religious-based idioms (6), loss of life style as reflected in metaphors (7), and loss of culture-bound expressions (8):

"دي حيلتها البلى الأزرق؟!" (3)

“... di Heelit-ha el-bala el- azraq?!"

this.fem has-she the-disease the-blue

“..this woman owns a penny?!” (Farahat's Republic)

"ثم عرف رمضان الطريق الى المستثفىالسري" (4)

"thuma 3arafa Ramadan al-tareeq ila al-mustashfa al-sirri".

then knew-he proper N. the- way to the-hospital the-secret.

"Ramadan then knew the way to the hospital for venereal diseases" (Abu Sayyid)

"و هل بدأت المسألة أيام العيد الصغير أو بعده؟" (5aqu

"wa hal bada'-at al-mas'alat 3aqib ayyaam al-3eed alsagheer aw ba3da-hu"

And did start-it the-problem after days the-feast thesmall or after-it

"he couldn't recall whether the problem started before or after the holy feast" (Abu Sayyid)

"قصدي صاحبها مجهول...لقيوا السر الالهي طلع منه لوحده ومن غير ما حد يكلمه" (6) "qasdi saHib-ha majhool... liqi-oo el-sirr el-laahi

Mean- I owner-its unknown... found-they the-secret the-divine

tili3 min-u liwaHdo wa min-ghair ma Hadd ykallim-u" 
came out of-him on its own and without neg. anybody talk-him

“...name unknown. Death of natural causes" (Faraha's Republic)

"ويحس بالقبعة وكأنها حجر الطاحونة يكتم أنفاسه" (7)

"wa yuHiss-u bel-qubba3ah wa ka'annaha Hajar eltaHoonah yktimu

And feels-he bythe- helmet and as if- it stone themill suffocate

anfaasa-hu"

breath-him

"and felt the helmet on his head as if it were a heavy weight suffocating him" (Abu Sayyid)

(8)

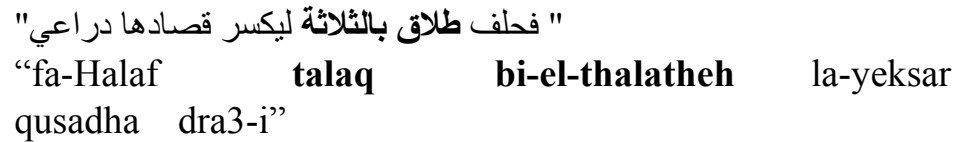

so-swore-he divorce in-the-three that-he-break

in return arm-my

"so he made a triple oath to divorce me unless he broke my arm" (Farahat's Republic)

The examples in this section show that although translation is functionally and communicatively successful, it suffers greatly losses of cultural implications. Example (3) continues with the context where the woman goes to the police station to report charges of robbery of her gold earrings and bracelets. The sergeant-major talks to another person commenting on her charges. Looking at translation, it successfully delivers the communicative message behind the literal meaning, yet it seriously disregards the social implications behind it. In order to clearly understand these implications, let us look more closely at its 
social and cultural implications. The idiom was originally used to refer to pestilence. People in the Arabic culture refer metaphorically to pestilence as the 'blue disease'. It is socially awkward and inappropriate to explicitly mention fatal diseases - particularly epidemic ones-before a patient or his family so as not to hurt their feelings. This reflects social solidarity and strong social ties among relatives and friends in the source culture. Other information implicitly present in the idiom - which might only be understood by source readersis the belief that when a person explicitly mentions a disease, $\mathrm{s} / \mathrm{he}$ is more likely to get it. This belief could be traced back to the preIslamic period, when people believed in the evil eye and genies as evil powers that transmit bad diseases. The implications of this source idiom were later extended to poverty. In (3), the woman is so poor that she does not even have that disease, which comes for free. This carries an implicit reference to a low social class. As noted, translation merely renders the communicative meaning, but loses all the cultural implications.

A different social attitude implicitly lost in translation is the attitude towards men in a patriarchal society. In example (4), the narrator talks about a husband who recently realized that he became sexually incapable. The implicitness in the source text was rendered explicitly into the target text. This is justified from a translational viewpoint, since it enables target readers to correctly decode the message. However, such implicit reference in the source idiom is not merely an issue of political correctness or appropriateness when talking about a taboo subject. Rather, it reflects the general social attitude towards men in the Arabic culture, where they are looked up to as the source of power and protection. Accordingly, going to the 'secret hospital' is associated with embarrassment, loss of the manhood image, and so a betrayal of the social concept.

Implicit losses in translation also reflect the loss of certain social practices. Example (5) shows how religion shapes the way of thinking in a predominantly religious society. The religious/cultural background of the example is that Muslims celebrate only two feasts: the first 
feast on the Muslim calendar is celebrated after the holy month of fasting. It is referred to as 'Ramadan feast' or the 'small feast' (due to its duration of three days). The second feast is celebrated after finishing one of the five pillars of Islam, i.e., pilgrimage, and is referred to as the 'big feast' because it lasts for four days.

In this example, the main character (the husband), being irritated and confused, is trying to figure out the time when his sexual problem started. In order to do so, he makes reference to the 'small feast' as his calendar (i.e., did the problem start before or after the small feast, knowing that the time span between the two feasts is usually seventy days). The value of this idiom lies in its reference to the Arabic lunar calendar -- a concept alien to the target culture. Nowadays, many Arab countries continue to make reference to the lunar calendar in organizing their daily-life events.

In other occasions, implicit losses occurred as losses of the religious-based idioms, i.e., idioms derived from the Islamic teachings. In example (6), the sergeant-major talks, in a sarcastic tone, about one of the cases filed in his police station, namely, a corpse found in a deserted yard. An analysis of the English translation of (6) reveals that although it successfully renders the communicative message behind the idiom, it suffers two pragmatic losses: the loss of the connotations meant by the source words, and the loss of the speaker's attitude (i.e., sarcasm). In order to understand the gravity of this loss, let us discuss how this idiom is interpreted by the source readers. Guided by their background knowledge of the religious beliefs prevalent in their culture, source readers know that Muslims believe in God as the ultimate and sole creator of everything. Accordingly, God places his secret in each person, i.e., the soul. This is culturally referred to as the 'divine secret' because only God has the power to give this secret, only God chooses to place the soul in the body, and only God himself determines when and where the person is to be born and would eventually die. So what is actually lost? Translation replaced the intended concept of death (as the act of God) by a new 
concept, which views death as a cause of nature, and an act of physical powers. In this case, translation betrayed Muslims' religious, social and cultural beliefs in the powers of God.

In short, idioms are the gems of the Arabic culture. They are loaded with cultural aspects and pragmatic values that are rooted in their social and religious contexts. This makes their translation challenging, and their loss from the text serious.

Example (7) also shows how metaphors are reflections of cultural ways of living. The reference in example (7) is to one of the ancient tools that later became a cultural heritage, namely the "stone mill'. The stone mill is a tool used by Arabs until the beginning of the last century to grind seeds. It is operated manually and is made of two heavy stones placed firmly on top of each other so that the grounded seeds will not be scattered and get out of the mill. In (7), the source author draws the association between the stone of the mill and the helmet on the character's head to reflect the images of heaviness and suffocation. Translation, on the other hand, not only loses this cultural image, but also neutralized the metaphor so that it even lost its aesthetic effect. This is the result of overlooking the metaphor's sensitivity to the communicational situation. It involves the shared knowledge and mutual expectations of the source author and the source readers of what is common (Dobrzynska 1995: 596). Using the 'mill stone' as a metaphor suggests that the Arabic culture was, and still largely is, an agricultural society where such tools are important. This is reflected in everyday language.

Example (8) is an instance of literal translation of the source item. The translation is elusive in the sense that it does not explain to the target readers the significance of the Arabic 'triple oath', which is semantically more loaded, and pragmatically more forceful than what the translation suggests. Such literal translation seriously and outrageously distorts the meaning behind the phrase. This example could be viewed - in agreement with Newmark (1991: 83) — as an instance of "lexical interference". In order to understand how 
translation causes a serious loss, we need first to get familiar with the non-verbal surroundings of the source expression. Pragmatically speaking, the connotations behind the 'triple oath' reveal a series of complex acts derived from the Islamic laws regulating marriage. The connotative background of 'triple oath' could be explained as follows: when a man takes a triple oath to divorce his wife, he suffers the penalty of losing her. That is to say, he cannot simply remarry her unless she remarries, goes on with her new life. If things do not go so well and the woman is divorced for the second time, only then, the man is allowed to remarry his divorced wife, if and only if she wishes to get back. It needs to be understood that the 'triple oath' is a complex process that emphasizes two values: marriage relationships are valuable and have to be respected, and that divorce should not be taken haphazardly. It should be noted, that the complexity of the Arabic 'divorce through a triple oath' is paradoxical. It might be easily understood as a single performative act/statement said three times - which is why it is an effective threat. In the source example, the husband understands the connotations behind his vow, and so made it conditional. That is, if his wife does not follow what he says, he will either divorce her or break her arm. The source reader, being familiar with such connotations in his native language/culture, would be able to follow the character's actions and words in a much more logical way.

The translation, on the other hand, renders the source expression as a mere wording of the man's vow. In this sense, what is translated is only the verbal part of the sign into another verbal sign. This gives a false impression of the significance of the sign, i.e., the man merely verbalized a strong oath. In addition, the translator mistranslates the word 'qusadha= in return' as 'unless', thus totally ignoring the optionality of either divorcing the wife or breaking her arm. It follows that translation is awkward because it ignores these implications, hence causes a double loss: a loss of the cultural implication and of the pragmatic force of the source expression. It is argued this 
incomprehensive in translation is due to the translator's over familiarity with the source language, where he unconsciously presupposes target readers' familiarity with what they read. In this regard, Nida and Taber (1974: 99) suggest "too much knowledge of the subject matter can be a deterrent to effective translation." All of the connotations above should have been supplemented by explanatory footnotes.

To conclude, implicit losses are losses of the essence of the source culture and its identity. The losses discussed above illustrate how culture is hidden in the literary heritage of its social attitudes, religious beliefs, surrounding environment, historical events, and cultural heritage. An explanation of these implicit values is essential to target readers in order to provide them with the pleasure of exploring the beliefs and attitudes of another different culture (which is the main purpose of literature after all). So, how would a translator provide this knowledge of hidden values for his target readers? It would be unwise, or unpractical to propose the infusion of these cultural information (between-the-lines reading) into the body of the translated text, where coherence of the target text could be completely distorted, and the resulting translation would violate communicative equivalence, one of the most basic functions in translation. Instead, I would suggest, along with Al-Qinai (1999: 239) and Farghal (1995a: 199), that in the translation of literary texts, cultural information should be highlighted and/or supported by explanatory phrases or notes that explain the customs, beliefs and attitudes that are unfamiliar to target readers. Next, we will discuss the third type of cultural losses, 'modified losses.'

\subsubsection{Modified Losses}

'Modified losses' refer to losses resulting from the replacement of cultural expressions in the source text by culturally equivalent expressions in the target text. Losses of this kind have a mild effect on the source text. In a sense, they are similar to implicit losses in 
not seriously affecting the theme of the message conveyed. However, they differ in that they achieve more cultural equivalence than implicit losses. Modified losses are indicators of how the two cultures in question reflect realities, and how people of one culture denote the world from their own perspectives. Modified losses compose a subhierarchy of losses representing: loss of proverbs (9), loss of honorifics: male-female addressee forms (10), and male-male addressee forms (11), and loss of cultural expression reflecting the source environment (12).

"وفي كل مرة كان يعود وكأننا يا بار لا رحنا ولا جينا" (9)

"wa fii kol marrah kaan-a ya3ood wa ka'ann-ana ya Bader

and in each time was-he return-he and as if- we hey proper.noun

la roH-na wa la jee-na" neg. went-we and neg. came-we "but each time it was all in vain" (Abu Sayyid)

(10) a. "مالك با سي رمضان"

"maa-lak ya si Ramadam" what-you hey sir proper.msc.n.

"What's wrong Ø Ramadan?"(Abu Sayyid)

b. "اسم اللة عليك يا خويا"

"ism Allah 3alyik ya khoo-ya..."

name God upon-you hey brother-my

"What's wrong, darling...?"(Abu Sayyid)

c. "اسم النبي حار سك يا ضنايا"

"Isim el-nabi Hars-ak ya dana-ya"

name the-prophet protect-you hey son-my

"May the prophet protect you, sweetheart" (Abu Sayyid) 
(11) a. "مالك يا ولية"

"ma-lik ya wleyyah"

what-you hey broad

"What's the matter, woman" (Abu Sayyid)

b. "و ايه يدخلك السيما يا بت"

"wa ayh ydakhal-ik el-seema ya bit"

and what go-you the-cinema hey girly

"and why do you go to the cinema, girl" (Abu Sayyid)

c. "يا شيخ فضك"

"ya shaikh fud-ak"

hey religious man forget-you

"Just forget it, brother" (Abu Sayyid)

(12)

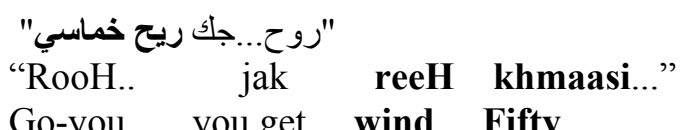

Go-you... you get wind Fifty

"Get lost!" (Farahat's Republic)

It has been discussed earlier how proverbs are records of cultural events. Here example (9) shows how proverbs are modified in translation. The English translation replaces the source proverb by a culturally equivalent expression. By so doing, it successfully delivers the message intended in the source text. Nonetheless, there is still a loss of the attitude and mode of thinking of the source culture. This source proverb in (9) describes originally the Arab's attitude towards traveling. It is used to describe disappointment, and the sharing of this feeling with a companion (here the reference is made to a male named Bader). In earlier periods, transportation was limited, and so traveling from one place to another was too much of a trouble. Nowadays, the proverb is used in the source culture metaphorically to express a disappointment for not achieving one's purpose, especially after taking many preparations. Culturally speaking, in spite of 
modernization, people extended the use of this proverb to a variety of contexts, but all convey the same message as that in the original proverb. That is to say, the proverb is extended both for its moral value, and for its aesthetic beauty.

Another form of modified losses is presented in (10), where honorific expressions/ social deixis come into play. Honorific expressions in the source culture-particularly in rural societies - are used in male-female interaction. They reflect the hierarchal relationship between the two, whereby women are inferior to men. It is noted that honorific terms are modified in translation. In (10), examples (a-c) illustrate the addressee forms used by women in addressing their husbands. These honorific terms were either explicitly lost (10a) (' $\mathrm{si}=\mathrm{sir}$ '), or modified $(10 \mathrm{~b}-\mathrm{c})$, whereby the term 'brother' was replaced by 'darling', and 'son' was replaced by 'sweetheart', respectively. Translation shows that the honorific expressions have been leveled out as a translation strategy to disambiguate terms of reference (Baker, 1996: 184), which makes their modification justified. It should be pointed out that the honorifics used by women denote a formal relationship between a woman and her husband, even when used as endearment expressions.

The examples in (11) show the other side of the coin. On the one hand, they illustrate how males use honorifics to address other males (11c), on the other hand, they show how males use different honorifics, with different attitudes, to address females (11a-b). The address forms in (a-b) are generally used to address women of a low social status. This reflects the speaker's derogatory attitude towards the woman. On the other hand, when limited to the context of husband-wife conversation, these honorifics function as endearment expressions. The paradox of this contradiction may be resolved by understanding the psychological mentality of Arab men. As mentioned earlier, in a conservative culture (Arabic), men are looked up to (11 c), while woman are looked down at. This is evident in the men's use of forceful words, and women's use of delicate, yet submissive forms. 
Finally, the cultural expressions reflecting the source environment were also subject to modified losses. Example (12) represents a cultural term of cursing, or what Levinson (1983: 42) calls 'imprecatives'. As noted, the translation successfully replaces the source idiomatic expression of swearing by an equivalent swearing in the target language. However, the loss is serious since the Arabic idiom carries far more cultural implications than a mere swearing. It implies the influence of the surrounding environment in shaping people's ways of thinking, and social practices (la parole). Originally, the Arabic expression 'reeH khmasi' refers to 'sirocco'. It refers to the phenomenon of the fifty-day summer wind storm. This wind storm starts in the Gulf area and crosses over the Arabian Desert to the neighboring Arab countries. It is very hot, dry, full of sand, and carries everything away. Later on, the degree of annoyance and irritation that people feel when this wind is around was extended to the undesirable presence of somebody. In (12), the speaker (officer) uses this image in the form of swearing wishing the tornado would carry away the person complaining, so that he would not have to listen to his complaints any more. This implicit loss of linguistic expressions and their dependency relationship on environment might be the result of what Sweetser (1995: 592) calls "broader cultural cognitive structures".

In sum, modified loses are mild losses because they slightly diverge from the communicative message in the source text, they express general truth, and so could be well assimilated into any culture. They are justified from a translation point of view, but are crucial from a cultural perspective. The fourth type of cultural losses is discussed below.

\subsubsection{Complete Losses}

As the term suggests, 'complete losses' are the result of a complete ignorance of the linguistic codes of the source text. Complete losses are purely culture-bound and unique to the source text, and so have 
no equivalents what so ever in the target culture. To put it differently, complete losses are losses of figurative verbal signs that may only be of prime pertinence to the Arabs (cf. Farghal 1995a: 201). Complete losses were limited in their occurrence to cultural similes (13), and idioms (14).

$$
\begin{aligned}
& \text { "وفتح دفتر المحاضر الكبير وكأنه يقتح بوابة المتولي وقال" } \text { "wa fataH-a daftar al-maHaadir al-kabeer wa } \\
& \text { "wa }
\end{aligned}
$$

\section{ka'annahu yaftaHu}

and opened-he notebook the-ledger the-big and

as if-he opens-he

\section{Bawwabet el-Metwalli wa qaal..." \\ gate the-proper $\mathbf{n}$. and said...}

"and opened the huge record ledger $\boldsymbol{\emptyset}$, saying..." (Farahat's Republic)

$$
\begin{array}{lllll}
\text { "حلق ايه با بت اللي خدوه؟ حُّق حوش" } & & \\
\text { "Halaq } & \text { ayh ya bit elli } \quad \text { Khado-oh? Hallaq }
\end{array}
$$

Hoosh?

Earring what hey girl that took-they? make a circle catch

"What kind of earrings did they take, girl? Ø" (Farahat's Republic)

The context of situation in example (13) describes the sergeantmajor, who opens his record ledger to file charges. The complete loss of the Arabic simile in the translation clearly does not affect the theme of the source message. What it causes, instead, is the loss of the similarity between actions and images, i.e., the similarity between people's daily activities and the 'Metwalli Gate'. This similarity is impossible to decode by target readers and so its translation would be meaningless. The 'Metwalli Gate' is one of the archeological arches in Cairo/Egypt that mark the crossing of liberation armies into the city. The reference to this gate in the Egyptian culture 
denotes the achievement of great acts. This simile is used in the example with a sarcastic attitude. The sergeant-major, who would never be promoted into a higher rank, thinks of himself as an important figure, just for the mere fact that he is a government employee. While, in fact, all what he does is a modest clerical job of recording charges. This simile reflects social status and cultural state of mind: a person employed in the government — even with a very low salary - is believed to be powerful and influential. Translation completely disregards these cultural details, and dismisses them as optional or rather trivial.

Example (14) illustrates the complete loss of cultural idioms in translation. The idiom is used in the context where the sergeantmajor questions the woman about her lost earrings. Again, what is completely lost is the pragmatic force of the speaker's utterance; hence the loss is serious. The speaker speaks with a sarcastic tone, judging the woman by her poor appearance, and so makes fun of the idea that she could possibly own something. The truth value of the Arabic idiom can be inferred by back translating it into 'make a circle and catch the run away thief'. This idiom is a reflection of the feelings of solidarity prevalent among neighbors in the Arabic culture. It expresses the values of neighborhood solidarity, familiarity, and strong social ties. Each neighbor feels it is his duty to protect his neighbor's property as if it was his own. Out of such solidarity, people use this idiom to call for help and support from passersby to catch a run away thief. In short, the decoding of such losses and the appreciation of their aesthetic effects require high levels of knowledge on the part of target readers. In this regard, Hart (1998) draws attention to the importance and invisibility of cultural context. She remarks "the translator must be particularly sensitive to the situationality of the original text, the socio-cultural context for which it was produced, and assess the differences with respect to the situation in which the mediated text is to be activated" (ibid: 147).

In this section, we have presented and classified cultural losses 
and showed how translation affected the cultural information of the source text in varying degrees ranging from a complete loss of information to an explicit violation of the meanings intended in the source text. In the following section, we will discuss cultural losses from a theoretical perspective.

\subsection{Discussion of Losses within the Etic-Emic Approach}

Let us start our discussion with the following question: are cultural losses the result of an etic approach to translation? Or is it a matter of misrepresentation of the emics of the source culture, and hence the cultural inequivalence?

An investigation of the translation strategies adopted shows that the translation product was communicatively successful. That is, it transferred the overall content of the source message to target readers. However, translation failed to transfer the deep/ implicit level of the source language, and the emics of the source culture. We argue that the translator assumed only one of the two functions that he should have fulfilled (both as an insider of the source culture and as an outsider of the target culture). He disregarded his role as a cultural insider of the source-culture, did not transfer his emic knowledge, and so has failed to complete the cycle of etic-emic-etic. In other words, the translator remained an outsider to both the source culture and the target culture. Pike (1990: 34) asserts this dual function of the translator: "just as the outsider can learn to act like an insider, so the insider can learn to analyze like an outsider". He explains that "to use the emics of nonverbal (or verbal) behavior I must act like an insider, to analyze my own acts, I must look at (or listen to) material as an outsider" (ibid: 34 ). In short, the lack of cultural equivalence that led to cultural losses occurred during the second sequence, where the translator failed to translate the emics of his source-language culture into the target culture.

The issue of whether the translator should be an insider (a native 
speaker of the source language), or an outsider (non-native speaker of the source language) is not as simple as it might look. It is assumed that if the translator is a native speaker of the source language-a 'local person' - he is expected to behave as a normal participant in the source culture, or as one who has obtained some etic training to help discover things about himself and his fellows, their actions, their feelings, their experiences (Pike 1990: 34). This suggests that the translator-being an insider in the source cultureunderstands the implications meant by the figurative language used by the source author. However, this was not the case here. There is evidence in the data that even though the translator is an insider, his translation did not render a successful emic representation of the source culture.

Being an insider translator has its own pitfalls. One of these pitfalls is the issue of familiarity. The translator might sometimes fall into the trap of being a "cognitive blinder". That is, when the translator's over familiarity with the source language leads him to assume/presuppose the target readers' familiarity with what they read. This makes the translator blind of what could be marked to target readers. By means of illustration, let us go back to example (1). The translator utilized his emic knowledge and transferred the source expression into the target culture merely as 'Thursday night', which results in an awkward translation. Since translation should be target-language oriented, it should focus on facilitating the understanding and the appreciation of the literary work by target readers. In order to achieve an optimal equivalence, it is suggested that the translator has to demonstrate his ability to translate on two levels of understanding: understanding the emics of the source culture, and understanding the emics of the target culture, and then relate both faithfully. To achieve this end, the translator has to account for a complex hierarchy of interconnected beliefs that represent a high-level emic. Once again, example (1) is an idiomatic expression whose meaning as a whole is different from the sum of the meanings of its parts. In this 
sense, it is marked, it carries symbolic implications, and it is sensitive to context. Accordingly, translation should account for the added/implied meanings, which according to Pike (1990: 35) can be present at very high levels of hierarchical structure.

Again, the loss in example (1) results from marginalizing the social context which reflects the attitudes, customs, and social beliefs (emics) of the source culture. The cultural implication behind 'Thursday night' is alien to target readers, its unfamiliarity is derived from the differences in the concept of weekend between the two cultures, and the non/or lack of existence of a shared knowledge, whereby the two cultures in question use different linguistic codes to address the same concept. In Pike's terms, “Appropriateness of an emic unit includes the feature of its relevant occurrence in relation to the total cultural pattern of an individual or society" (1990: 29). However, this issue of familiarity is more complex than simply resolving unfamiliarity and rendering it familiar. The source idiom is marked for two reasons: first, it is culturally-bound, and second, it is composed of a complex hierarchy of interconnected beliefs that need to be understood on the higher level of emics, such as context and implicature. A decoding of the idiom requires a familiarity with its context as to when and how native speakers use it before we can move on to the higher level of implicature.

In brief, the emic approach to translation has four advantages. First, it permits an understanding of the way in which a language or culture is constructed. Second, it helps one understand individuals' attitudes and their daily lives (Pike 1990). Third, it produces cultural understandings that enable better communication with cultural insiders. Finally, it gives a valuable appreciation of the extent of human creativity. Before concluding this paper, it is worth looking at cultural losses from the perspective of Markeness theory. This theory is believed to give a fresh perspective regarding decision-making in translation. 


\subsection{Cultural Losses and the Markedness Continuum}

In its broadest sense, markedness theory is based on the idea of opposition, according to which the two poles of a semiotic opposition consist of an "unmarked" and a "marked" form. The unmarked form is the more natural and often the more frequent one, it has a general interpretation, and may be substitutable for the meaning of the marked term in some contexts. The marked term, on the other hand, has an additional and more specific morphological feature (Battistella 1990). As argued earlier, cultural losses occurring in the translation of literary texts are losses of the source-culture expressions that have deep/symbolic values. Accordingly, cultural losses are marked on the grounds of the unmarked surface/truth-value expressions.

Assuming a linear continuum of markedness, cultural losses are ranked from the least marked to the most marked, as follows: complete losses, modified losses, implicit losses, and explicit losses. Complete losses are the least marked, while explicit losses are the most marked. This proposed hierarchy of cultural losses is based on the level (deep/surface) on which the loss occurs and the degree with which the loss of cultural information is crucial to the content of the source message. A summary of the hierarchy of cultural losses is presented in table (1) below:

Table 1. Summary of the Cultural Losses in Relation to the Markedness Continuum

\begin{tabular}{cc}
\hline Type of Losses & Markedness Continuum \\
\hline Complete & Least-Marked \\
Modified & Mid-Low Marked \\
Implicit & Mid-High Marked \\
Explicit & Most-Marked \\
\hline
\end{tabular}


The least marked of cultural losses is 'complete losses'. They are, by and large, losses of cultural metaphors and idioms, which are extremely culture-bound. There are two reasons behind their complete loss. First, there is the difficulty of capturing all the contextual hierarchies that idioms entail and at the same time keeping up with the coherence of the text. The second reason is that idiomatic expressions might have been considered as purely aesthetic. Complete losses do not substantially pose difficulties in the decoding the communicative message of the source text, and so are the least marked.

Modified losses are more marked than complete losses but less marked than implicit and explicit losses, they rank second on the continuum. Modified losses could be looked at from two perspectives: one the one hand, they are the only kind of losses (discussed in this article) that achieve an optimal equivalence. This is due to their replacement by culturally equivalent expressions in the target text. In this sense, the marked cultural losses would be less marked since target readers would be reading expressions, whose contexts they understand. On the other hand, target readers-while reading the modified translation-would lose tract of the source culture (i.e., they would remain outsiders of the source culture). In spite of this, modified losses can be easily assimilated since the loss of cultural information required for their understanding is minimal.

Implicit losses rank third on the markedness continuum. Their loss is mainly on the deep level of the source language, accordingly, their translation remained communicative and the degree of cultural information lost did not block the understanding of the content of the source text. However, implicit losses are marked in the sense that they require extra effort on the part of target readers due to their "between- the-lines" reading.

Finally, explicit losses are the most marked in terms of the level affected, and the degree of loss to the source message. Explicit losses affect both the surface, and the deep levels of source language. 
This lead to the loss of cultural information needed for the understanding of the content of the source message. Explicit losses are the most marked since they were translated in the absence of shared knowledge, as well as the nonexistence of equivalents in the target culture.

In conclusion, the application of markedness theory to translation has its own merits. It provides the translator with a tool or criterion to determine the quality and quantity of the cultural information of the source message. That is to say, after assuming his role as a cultural insider and translating accordingly, the translator can use the markedness continuum as a test to determine the seriousness of the loss and make informed decisions as to what may be lost (with the least damage). In this case, the translator would minimize major losses and yield a better translation.

\section{Conclusion}

This article has focused on cultural losses occurring in the translation of Arabic literary texts. These losses were losses of the cultural information that are inherent on the symbolic/deep level of the source text. As such, they continue to occur even when linguistic equivalence is achieved (i.e., they do not block the understanding of the meaning intended in the source language). This study showed that some of the translation strategies adopted caused a distortion of the message intended in the source text, and so resulted in a translation that was unjust to the source and target texts alike.

The two theoretical frameworks presented in this article (the eticemic approach and markedness theory) are two distinct yet related and helpful approaches to cultural translation of literary texts. While the former defines the role of the translator as a cultural insider, the later provides the translator with insights into the degree with which the loss may affect the source message and guide him in making informed decisions to yield better results and more faithful and interesting translation. 
42 Translation and Cultural Equivalence: A Study of Translation Losses

\section{References}

Al-Qinai, J. 1999. Explication vs. Implication in English-Arabic Translation. Theoretical Linguistics 25 (2/3), 235-255.

Anderson, M. 2003. Ethnography as Translation. In S. Petrilli (ed.),

Translation Translation: Approaches to Translation Studies 21 389-396. Amsterdam: Rodopi.

Bailey, C. 1996. Essays in Time-Based Linguistic Analysis. Oxford: Clarendon Press.

Bakalla, M. 1984. Arabic Culture: Through its Language and Literature. London: Kegan Paul International.

Baker, M. 1996. Corpus-Based Translation Studies: The Challenges That Lie Ahead. In H. Henas \& J. Sagar (eds.), Terminology, LSP and Translation: Studies in Language Engineering by H.L.

Somers. Amsterdam: John Benjamins.

Battistella, E. 1990. Markedness: The Evaluative Superstructure of Language. New York: State University of New York Press.

Berry, J. 1990. Imposed Etics, Emics, and Derived Etics: Their Conceptual and Operational Status in Cross-cultural Psychology. In T. Headland et al. (eds.), Emics and Etics: the Insider/ Outsider Debate 84-99. Newbury Park, CA: Sage Publications.

Brown, M. \& B. Rosenberg. 1998. Encyclopedia of Folklore and Literature. Santa Barbara, CA: ABC-CLIO.

Danesi, M \& P. Perron. 1999. Analyzing Cultures: An Introduction and Handbook. Bloomington, IL: Indiana University Press.

Dobrzynska, T. 1995. Translating Metaphor: Problems of Meaning. Journal of Pragmatics 24, 595-604.

El-Khadem, S. 1994. Five Innovative Egyptian Short Stories. Fredericton: York Press.

Farghal, M. 1995a. Jordanian Proverbs: An Ethnographic and Translational Perspectives. Sendebar 6, 197-208. . 1995b. Lexical and Discoursal Problems in English-Arabic Translation. Meta XL (1), 54-67. 
Grice, H. 1975. Logic and Conversation. In P. Cole \& J. Morgan (eds.), Syntax and Semantics 3: Speech Acts 41-58. New York: New York Academic Press.

Hart, M. 1998. Translation of the Sense of Humor: Literary Limitation. Unpublished dissertation, Universidad de Las Palmas de Gran Canaria.

Headland, T. 1990. Introduction: A Dialogue between Kenneth Pike and Marvin Harris on Emics and Etics. In T. Headland et al. (eds.), Emics and Etics: the Insider/Outsider Debate 13-27. Newbury Park, CA: Sage Publications.

Hockett, C. 1958. A Course in Modern Linguistics. New York: Macmillan.

Idris, Y. 1991. Three Egyptian Short Stories. Fredricton: York Press. Katz, J. \& P. Postal. 1963. Semantic Interpretation of Idioms and Sentences Containing Them. Quarterly Progress Report 70, 275-82.

Lakoff, G. \& M. Johnson. 1980. Metaphors We Live By. Chicago, IL: Chicago University Press

Larson, M. 1984. Meaning-Based Translation: A Guide to CrossLanguage Equivalence. Lanham: University Press of America.

Levinson, S. 1983. Pragmatics. Cambridge: Cambridge University Press.

Lyons, J. 1995. Linguistic Semantics: An Introduction. Cambridge: Cambridge University Press.

Makkai, A. 1972. Idioms Structure in English. The Hague: Mouton. Newmark, P. 1991. About Translation. Clevedon: Multilingual Matters. Nida, E. \& C. Taber. 1974. The Theory and Practice of Translation. Leiden: E.J. Brill.

Pedersen, V. 1988. Essays on Translation. Studies in Business Language 16. Copenhagen: Erhverus økonon. SIC Forlag. Pike, K. 1954. Language in Relation to a Unified Theory of the Structure of Human Behavior Part 1 (Preliminary Edition). glendale, CA: Summer Institute of Linguistics. 
44 Translation and Cultural Equivalence: A Study of Translation Losses

Strässler, J. 1982. Idioms in English: A Pragmatic Analysis. Tübinger Berträge zur Linguistik 185. Tübingen: Gunter Narr Verlag.

Sweetser, E. 1995. Metaphor, Mythology, and Everyday Language. Journal of Pragmatics 24, 585-593.

Toury, G. 1986. Translation: A Cultural Semiotic Perspectives. In R. Sebeok (ed.), 73, Encyclopedic Dictionary of Semiotics 3 vols. Berlin \& New York: De grugter.

Trask, R. 1999. Key Concepts in Language and Linguistics. London: Routledge.

Way, E. 1991. Knowledge Representation and Metaphor: Studies in Cognitive Systems 7. Dordrecht: Kluwer Academic Publishers.

Weinreich, U. 1969. Problems in the Analysis of Idioms. In J. Puhvel (ed.), Substance and Structure of Language. Berkeley, CA: University of California Press. 